Available online at www.iponlinejournal.com

\title{
Impact of sterilization on the fracture resistance of Hyflex instrument's used in different simulated canals
}

\section{Emre Övsay}

Yeditepe University Faculty of Dentistry Dept. of Endodontics İstanbul/Turkey

\begin{abstract}
To evaluate the cyclic fatigue and the fracture resistance of engine-driven Hyflex instruments used in different simulated canals. A total of 90 Hyflex instruments size 25 used during root canal were tested. Each group was divided into 3 subgroups (n=10). The first group sterilized before usage, the second group used as factory prepared and the third group used 10sec for shaping then it was sterilized and used again to be tested in simulated canals with $60^{\circ}, 45^{\circ}$ and $90^{\circ}$ angles of curvature and a $3 \mathrm{~mm}$ radius at a constant speed of $500 \mathrm{rpm}$ and 2.5 $\mathrm{nm}$ torque until they were fractured. The time of fracture for each instrument was recorded. The data was compared using one-way analysis of variance followed by Anova test. Approximately one third of instruments became deformed as a result of usage. The instruments used then sterilized and re-used again are resulted in a significantly longer cyclic fatigue life $(\mathrm{P}<0.0001)$ when compared with the ones which were sterilized before usage. No difference of cyclic fatique was found between the length of the instruments after breakage.

Conclusions: Multiple use of size 25, 0.08 taper Hyflex instruments are reliable to use after sterilization.
\end{abstract}

Keywords: Hyflex, Cyclic fatique, Fracture resistance.

\section{Introduction}

The technology of the Ni-Ti instruments are developed to be more flexible, fracture resistant and efficient in canal shaping. Hyflex files includes the technology that changes the file's physical properties by heat treatment. ${ }^{1}$ Hyflex is an instrument produced from CM wire that can re-shape its memory with thermomechanical treatment and more flexible compared to other classic Ni-Ti files. Several studies showed that the endodontic files produced with CM wire are more resistant to cyclic fatique. ${ }^{2}$

The manufacturer claims that the Hyflex instruments can reform their original shape after heat sterilization. ${ }^{3}$ The manufacturer recommends two sequences for preparing canals using HyFlex CM: crown down and single length technique. ${ }^{3}$ Reports on the rate of fracture or deformation of HyFlex CM are limited when these two sequences are compared. Also a disadvantage of single use of instruments is increased costs, as more instruments will be used for theraphy.

\section{Materials and Methods}

A total of 90 Hyflex instruments size 25 used during root canal were tested. Each group was divided into 3 sub groups $(n=10)$. The first group sterilized before usage, the second group used as factory prepared and the third group used $10 \mathrm{sec}$ for shaping then it was sterilized and used again to be tested in simulated canals with $60^{\circ}, 45^{\circ}$ and $90^{\circ}$ angles of curvature and a $3 \mathrm{~mm}$ radius at a constant speed of $500 \mathrm{rpm}$ and $2.5 \mathrm{~nm}$ torque until they were fractured.

The files were exposed to cyclic fatigue test using a stainless steel device produced for and already used in previous studies. 9,10 The specialized stainless steel block enabled the files to rotate freely within an artificial canal with $3 \mathrm{~mm}$ radius at a constant speed $(500 \mathrm{rpm})$ and torque $(2.5 \mathrm{~nm})$. The plastic top face cover over the apparatus allowed the visuality of the files rotating inside the canal and the removal of broken files during instrumentation. To reduce friction as the metal instrument contacted the metal canal walls, synthetic oil (Wd no:40; USA) was used. The instruments were rotated with MM control unit (Micromega, France) which has a particular activity to control the angles of rotation in clockwise movement.

The time of fracture for each file was calculated and the data was compared using one-way analysis of variance followed by Anova test.

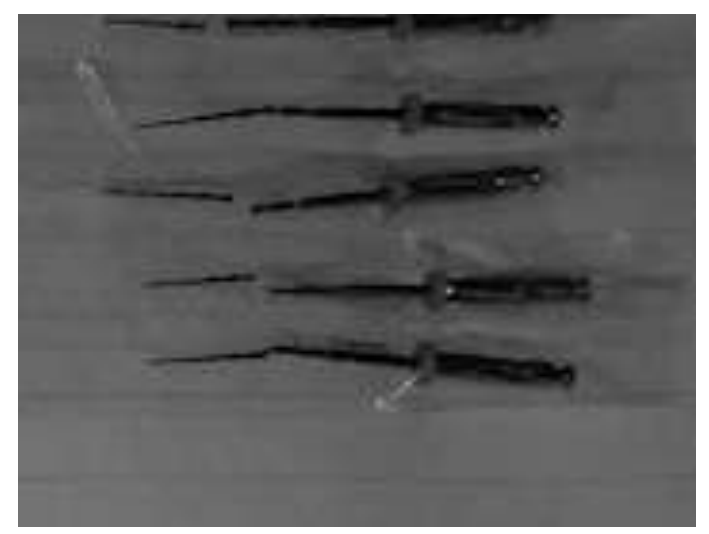

Fig. 1: The broken Hyflex instruments

\section{Results}

Approximately one third of instruments became deformed as a result of usage. The instruments used then sterilized and re-used again are resulted in a significantly longer cyclic fatigue life $(\mathrm{P}<0.0001)$ when compared with the ones

\footnotetext{
*Corresponding Author: Emre Övsay, Yeditepe University Faculty of Dentistry Dept. of Endodontics, İstanbul/Turkey

Email: emreovsay@yahoo.com

http://doi.org/10.18231/j.ijce.2019.021
} 
which were sterilized before usage. No difference of cyclic fatique was found between the length of the instruments after breakage.

\section{Discussion}

The aim of this study is to evaluate the cyclic fatigue and the fracture resistance of engine-driven Hyflex instruments used in different simulated canals. The developing new phase of alloys NiTi technology and manufacturing processes has led to a new generation of nickel titanium instruments. More flexibility ${ }^{4}$ and more resistance to cyclic fatigue $^{5}$ cause the instrument to be more durable. File fracture can usually be seen during canal instrumentation. There are multiple factors that cause file fracture, one of the main cause is the cyclic fatigue. ${ }^{6}$ The previous studies have used cylindrical metal tubes of at least $1 \mathrm{~mm}$ in diameter with differing radii and angles of curvature..$^{7-9}$ whereas others have used a sloped metal block to simulate different angles.

Within the limitations of this study, the hyflex instruments used then sterilized and re-used again are resulted in a significantly longer cyclic fatigue life when compared with the ones which were sterilized before usage. This conclusion shows the importance of taper level and design and the sterilization effect. Also the new CM wire technology has an effect on this outcome. Mostly curved root canals, files that have lower taper degree should be preferred and clinicians should avoid over-shaping of apical part.

In this study there is no human participants and animals involved. This study was not supported by any foundation.

\section{Source of Funding}

None.

\section{Conflict of Interest}

None.

\section{References}

1. Gutmann JL, Gao Y. Alteration in the inherent metallic and surface properties of nickel-titanium root canal instruments to enhance performance, durability and safety: a focused review, Int Endod J 2012;45(2):113-28.

2. Shen. Current Challenges and Concepts of the Thermomechanical Treatment of Nickel-Titanium Instrument. JOE 2013;39(2).

3. Coltene manufacturer broshure.

4. G. Gambarini G. Plotino N. M. Grande D. Al-Sudani M. De Luca L. Testarelli Mechanical properties of nickel-titanium rotary instruments produced with a new manufacturing technique, 2010

5. Kim.Outcome of endodontic surgery: a meta-analysis of the literature--part 1: Comparison of traditional root-end surgery and endodontic microsurgery. $J$ Endod 2010;36(11):1757-65

6. Current Challenges and Concepts of the Thermomechanical Treatment of Nickel-Titanium Instruments, JOE 2013;39(2).

7. Pruett JP, Clement DJ, Carnes DL Jr. Cyclic fatigue testing of nickel-titanium endodontic instruments. $J$ Endod 1997;23(2):77-85

8. Yared GM, Bou Dagher FE, Machtou P. Cyclic fatigue of ProFile rotary instruments after clinical use. Int Endod $J$ 2000;33(3):204-7.

9. De-Deus G, Moreira EJ, Lopes HP, Elias CN. Extended cyclic fatigue life of F2 ProTaper instruments used in reciprocating movement. Int Endod J 2010;43(12):1063-8.

How to cite this article: Övsay E. Impact of sterilization on the fracture resistance of Hyflex instrument's used in different simulated canals. Indian $J$ Conserv Endod 2019;4(3):91-2. 